\title{
The Role of Expectation in Job Search and Firm Size Effect on Wages*
}

\author{
by \\ Takako Fujiwara-Greve ${ }^{\dagger}$ \\ Department of Economics, Keio University \\ 2-15-45 Mita, Minatoku, Tokyo 108-8345, Japan \\ and \\ Henrich R. Greve \\ Institute of Policy and Planning Sciences, University of Tsukuba \\ 1-1-1 Tennodai, Tsukuba-shi, Ibaraki 305-8573, Japan
}

\begin{abstract}
One of the most puzzling facts in economics is the firm size-wage effect. After controlling for the observable characteristics of workers (age, gender, education, residence etc.), firms (industry, occupation, work conditions etc.) and negotiation effect (unionization), one still finds that the sheer size of a firm increases the wage, contrary to the one-good one-price doctrine.

We provide a simple dynamic game model of wage determination to give a new rationale to the firm size-wage effect. We think that the wages are not market clearing prices but strategies by firms. Firms choose wages to control workers search behavior. The essential feature of the model is that a large firms history of wages is observable to all the current and future workers, while a small firm is not visible and only its current offer is observable. Therefore a small firm is expected to be a myopic low-wage payer, and its workers will search for outside offers and quit often. A large firm can prevent search if it maintained a high wage throughout the past, by making workers expect high future wages. In this way, the firm size determines the worker expectations of its future wages, which changes the quit rate and equilibrium wages.

To give additional support to our theoretical result, we test a new aspect of firm size-wage effect. Since the effect on wage levels are extensively studied, we derive two main hypotheses on wage gains after job changes. (H1) The proportion of firms that are larger than the previous employer increases the wage gain. (H2) The size of the previous employer decreases the wage gain. The firm size distribution effect (H1) is a new test. We obtain supports for both. Thus we conclude that the wages are strategies and affected by how workers utilize the firm size information in changing jobs.
\end{abstract}

JEL classiffcation number: C23, C73, D83, J30.

Key words: Firm size, Wage, Search, Game, Turnover

${ }^{*}$ We thank David M. Kreps, James N. Baron, Hideshi Itoh, and seminar participants at Tokyo Center for Economic Research, Kobe University, and Northwestern University for helpful comments.

${ }^{\dagger}$ Corresponding author. Phone: + 81-3-3453-4511, ex 3220. (From March 19, 2000, +81-3-5427-1295.) Fax: +81 -3-3798-7480. E-mail:takakofg@econ.keio.ac.jp 


\section{Introduction}

One of the famous "puzzles" in economics is the firm size-wage effect. There is ample evidence (Lester, 1967, Brown and Medoff, 1989, Abowd et al., 1999 and Bayard and Troske, 1999) that firm size increases the wages after controlling for work conditions (industry, occupation, region, dangerous work, etc.), worker characteristics (education, gender, age, experience, etc.), and negotiation effects (unionization). If labor service is a commodity which is traded based on its price (wage), the job and worker characteristics should identify a single commodity and therefore a single price (wage) should prevail. The reality is, however, that the same person doing the same task can be paid differently at different firms, and overall the sheer size of the employer has a positive effect on wages, as Thaler (1989, p. 181) describes:

A few years ago we hired a new secretary in my department. She was smart and efficient and we were pleased to have her. Much to our dismay, after just a few months she was offered and accepted a job from an IBM facility in a nearby city. She told me that she had been on a waiting list there for a year or so, and would be a fool to turn IBM down since they paid so much more than any of the other local employers. I wondered at the time whether her marginal product typing IBM interoffice memos could be that much higher than it would be typing manuscripts and referee reports, and/or why IBM should find it profitable to pay much more than the going wage.

Most of the proposed explanations of the firm size-wage effect fall into two lines of thought. (1) Unobserved differences (Bayard and Troske, 1999; Troske, 1999): There can be factors affecting wages that are not measured in the data and related to firm sizes. Weiss and Landau (1984) suggest that large firms have higher hiring standards than small firms. However, Torske (1999) rejects this hypothesis after showing that the firm size-wage effect remains after controlling for worker skills. This work confirms earlier work on the firm size-wage effect (e.g., Brown and Medoff, 1989) which found a remaining firm size-wage effect after controlling for various proposed explanations. Thus, theorists need to continue searching for factors that affect the wages and are related to firm size. 
(2) Efficiency wage: This theory assumes that the labor is not traded like a commodity, but induced by the firm's strategic wage setting (e.g., Shapiro and Stiglitz, 1984). A firm pays wages to reward workers' effort and threatens against shirking by firing. Bulow and Summers (1986) suggest that large firms cannot monitor workers as well as small firms, and thus pay more for the same work. While this is compatible with workers' incentives, it is not compatible with firms' incentive to improve the monitoring to avoid unnecessary rewards. Moreover, large firms have stronger monitoring than small firms (Kalleberg and Van Buren, 1996). Burdett and Mortensen (1998) and Coles (1998) formulate dynamic strategic wage-setting models where high wages induce high effort and low quit rate and therefore the size effect is a result of the high wage. Their models assume that a firm is indifferent among many wage levels to generate multiple equilibrium wages. However, it has been empirically shown (e.g., Abowd et al., 1999) that large firms and high-wage firms are more profitable, so the equal profit assumption is in doubt.

In this paper we improve upon these two ideas. We make a simple game between a firm and homogenous workers, where each worker can quit by taking an outside offer, ${ }^{1}$ based on Fujiwara-Greve (1999a). In each period the firm sets a wage level strategically to control workers' turnover rate, and the current worker forms an expectation on the firm's future wages to decide whether to search for an outside offer. The strategic wage setting corresponds to the efficiency wage idea. We also assume that a large firm's past wages are observable to all the current and future workers, while a small firm is not so visible and only its current wage is observable. The difference in observability is the factor that has not been incorporated in previous models but is shown to affect the equilibrium wages.

The observability of firm behavior affects equilibrium wages as follows. A firm cannot commit to future wages, and therefore the workers' expectation of the future wages determines the quit rate. Workers form expectations using available signals ${ }^{2}$ of the firm's behavior. Small size or a low wage in the past are considered to be signals of low future wages. Large size and high

\footnotetext{
${ }^{1}$ Although the ability to quit is clearly a normal feature of the employment relations, it is unusual in game theory. In the ordinary game framework, the set of players is fixed throughout the game, while in our game there is an exit option. For a general analysis of games with outside offers, see Fujiwara-Greve (1999b).

${ }^{2}$ Our idea is similar to (the reverse of) Spence's singalling model (1974) where workers choose their education levels to signal their abilities. In our model, however, there is no incomplete information, or "types" of a firm. Hence a signal means just an observation of the past actions and the firm size.
} 
wages throughout the past are signals of high future wages. We show that these expectations are confirmed, and there are two kinds of subgame perfect equilibria with stationary equilibrium wages:

[Myopic Equilibrium] Regardless of the firm size or its past wage offers (if observable), the firm always offers the minimum wage and the workers always search and quit often. In this equilibrium, the strategies by the firm and the workers are myopic and the past wage information is not utilized even if it is available. (Proposition 2.)

["Reputation" Equilibrium $\left.{ }^{3}\right]$ If the firm is large, it always offers a high wage and its workers do not search. If the firm is small, or if a large firm offered a low wage (an off-path behavior), they go to the myopic equilibrium. The logic behind this equilibrium is that workers' expectation (or the firm's reputation as a high wage payer) can collaps forever once a large firm sent a bad signal, a low wage. Hence a large firm chooses between maintaining a high-wage reputation or offering a low wage and going to the myopic equilibrium. It is shown that if the turnover cost is not too low, a large firm prefers to prevent search. A small firm does not have a chance to reduce the turnover cost because it cannot change the worker expectation significantly. Hence the size difference generates equilibrium wage difference. (Proposition 3.)

Thus we show that firm size affects equilibrim wages via an observability difference which influences worker expectations. It is intuitive that a large firm is visible to the public and therefore is careful about its behavior that affects its long-run reputation, while a small firm cannot influence the public opinion about its behavior and thus is myopic. To support our theoretical conclusion, in the second half of the paper we give new evidence that firm size affects wages as predicted by our model but not by alternative models of the firm-size wage effect.

We focus on the firm-size effect on wage gains after job changes, since the firm-size effect on wage levels are extensively studied. Wage gains are strongly affected by workers' strategic search. We derive and test the following hypotheses: (a) Given the current employer's size, if the outside offer distribution has many firms in the larger size category than the current employer, then a worker becomes selective (because it is a good opportunity set) and only takes a large

\footnotetext{
3The term "reputation" here means a trigger strategy. Our game has complete information and is thus different from the incomplete information models of reputation. See Fudenberg and Tirole (1996) for general reputation models, and Martinelli (1997) for an adverse-selection, moral-hazard model of firm reputation.
} 
wage gain when changing firms. Therefore the average wage gain after job changes increases when there is a higher proportion of larger firms. (b) Given the outside offer distribution, if the current employer is large, then the worker cannot improve the wages by a large margin when changing firms, because there are not so many larger (i.e., higher wage) firms to move to. Therefore the average wage gain after job changes decreases as the current employer's size is larger.

Prediction (a) is unique to our model. If job searchers do not take into account the size distribution of potential employers, there should not be a correlation between firm size distribution and the wage changes, so this is a new prediction derived from the model and not shared by other models. For example, if the wages are market clearing prices, there should not be an effect of size distribution. If the wages are set for the firm's profit maximization only, there should not be the size distribution effect either. Our model predicts that there is an interaction between workers strategic search and firms' long-run profit maximization, which leads to the firm-size distribution effect on wages. (b) is a standard effect of firm size but on the wage gains instead of on the wage levels. Support for (b) strengthens evidence for the firm size effect in general.

Using a unique dataset ${ }^{4}$ that records detailed work histories of almost 3000 Norwegian men, we find support for both implications. We control for the usual observable characteristics of workers and jobs. We obtain support for both (a) and (b). Therefore the result implies that wages are strategies, that is, accepted offers by the workers who make search decisions based not only the current employer's size but also on their opportunity set (the firm size distribution). Our other empirical results are standard and consistent with the literature. Thus, this paper makes a theoretical contribution to the wage determination models by introducing the effect of worker expectations driven by the firm size and observability of firm behaviors, and an empirical contribution by showing that wages are affected by the distribution of firm sizes in an industry and how workers move strategically among firms.

\footnotetext{
${ }^{4}$ As Bayard and Troske (1999) noted, insufficient data on both workers' characteristics and employers' has been a problem in examining the detailed properties of firm size-wage effect.
} 


\section{Job Search Game with Observability Difference}

\section{$2.1 \quad$ Model}

The players of the game are a firm and a sequence of workers it hires for a position in such a way that at any point of time $t=1,2,3, \ldots$, one person is hired. Multiple positions at the firm is a straightforward extension with the interpretation that the firm plays an independent game for each position. The firm has a fixed size, large or small, and the size is observable to all workers. All the players are infinitely lived and discount the future payoffs with factor $\delta \in(0,1)$. At the beginning of the game, the firm has a worker in the position. To begin the first period, the firm offers a wage level $w_{1} \in[\underline{w}, \infty)$ for the next period, but also pays $w_{1}$ as the initial payment. The level $\underline{w}$ is the minimum wage. Knowing the next period wage and the size of the firm, the current worker decides whether to search for an outside offer (with cost $s /(1-\delta)$ where $s>0)$ or not to search (with no cost). At the same time the worker produces a value $v$ to the firm. An outside offer is a stationary ${ }^{5}$ income sequence $x, x, x, \ldots$ and $x$ is independently and identically distributed according to a cumulative distribution function $F$ over a compact interval $[\underline{w}, \bar{w}]$ with density $f$. If the worker accepts the offer $x, x, x, \ldots$, he/she leaves the firm at the end of the period and starts receiving $x$ thereafter, and the firm has to incur cost $c>0$ to hire a new worker at the beginning of the second period. With a new worker, the second period is just as the first period of the game. If the current worker did not quit, the next period starts with the same firm-worker pair and the firm pays the promised wage $w_{1}$ and makes a new promise $w_{2} \in[\underline{w}, \infty)$ for the third period. After the third-period wage offer by the firm, the current worker chooses whether to search or not, and the game continues this way over the infinite horizon $t=1,2,3, \ldots$. Past outside offers cannot be recalled, and a worker who searched does not necessarily accept the offer he/she got for that period. The workers have identical productivity $v$ and outside offer distribution $F$. Figure 1 shows the timing of the actions and offers.

\section{$===$ Insert Figure 1 about here. $==$}

The firm's stage payoff depends on whether it has a new employee and its wage offer in the

\footnotetext{
${ }^{5}$ One can interpret a stationary outside offer being another stationary equilibrium of a game with another employer. It is straightforward to extend the model for a general sequence of an offer and the similar two equilibria obtain.
} 
past $w_{t-1}$ and this period $w_{t}$.

$$
\Pi_{t}= \begin{cases}v-w_{t}-c & \text { if the current worker is new } \\ v-w_{t-1} & \text { otherwise. }\end{cases}
$$

A worker's stage payoff at period $t$ depends on the firm's past wage offer $w_{t-1}$, current offer $w_{t}$ (depending on whether he/she is a new employee) and whether he/she searches. A hired worker's stage payoff is

$$
W_{t}= \begin{cases}w_{t} & \text { if he/she is a new employee and does not search } \\ w_{t}-\frac{s}{1-\delta} & \text { if he/she is a new employee and searches } \\ w_{t-1} & \text { if he/she is a continuing employee and does not search } \\ w_{t-1}-\frac{s}{1-\delta} & \text { if he/she is a continuing employee and searches. }\end{cases}
$$

Once he/she accepts an offer $x, x, x \ldots$, his/her stage payoff is $x$ thereafter.

Both the firm and the workers maximize the total discounted expected payoffs over the infinite horizon. The players are assumed to know the payoff functions of all the players, workers' outside offer distribution, and the timing of the game. We assume that workers' search decisions and realization of outside offers are only observable to the relevant worker, which is realistic. Quit decisions are naturally observable to the firm.

Moreover we assume that if the firm is large, the entire history of the firm's wage offers is observable to the current and future workers, while if the firm is small, only the currently standing offer is observable to the workers. (For $t=1$, the only information is the firm size before the firm makes the first offer $w_{1}$.) Therefore, we distinguish the history in period $t$ on which the players base their actions, depending on whether the firm is large or small. If the firm is large, the history at (the beginning of) period $t$ is all the past offers until the last period, $\left\{w_{1}, w_{2}, \ldots, w_{t-1}\right\}$, and if the firm is small, the history at $t$ is only the currently standing offer $w_{t-1}$, if its worker did not quit last period. If a small firm has a new employee, the only information available is its size before the firm's offer. ${ }^{6}$ In each period, the firm chooses the wage offer contingent on the relevant history. Since the worker uses the wage offer in the search and acceptance decision, the wage offer controls the turnover rate and the firm's turnover cost. The current worker makes the search decision and acceptance decision of a realized offer based not only on the firm size, the history at $t$, and the next-period wage offer, but also on his/her

\footnotetext{
${ }^{6}$ The observability difference assumption is not necessary to generate multiple equilibrium wages, as FujiwaraGreve (1999a) gives a symmetric-firm model with equilibrium wage differentials. The observability difference makes it impossible for a small firm to make a reputation and thus to go to the high-wage equilibrium.
} 
expectation of the future wages at the firm. In equilibrium, the expectation must be confirmed by the firm's actual strategy.

\subsection{Subgame Perfect Equilibria}

Although this game has a stochastic element of the outside offers, the uncertainty is resolved in each period and the worker cannot recall the past offers to change actions later. We can then use the subgame perfect equilibrium concept. ${ }^{7}$ In the following we focus on equilibria with stationary equilibrium wages to examine the time-invariant firm size-wage effect.

The subgame perfect equilibria with stationary equilibrium wages are constructed as follows. First, suppose that a worker expects that the firm will offer a stationary wage $w, w, w, \ldots$ Then an optimal strategy is either to search every period with a stationary reservation level (to be computed below) in the acceptance decision or never to search. Notice that if an outside offer $x, x, x, \ldots$ is worth accepting, then any offer $y, y, y, \ldots$ such that $y \geq x$ is also acceptable. Thus the optimal acceptance decision has the reservation level property such that any offer not less than a reservation level is accepted. Second, given the workers' optimal strategy, we show that a small firm or a firm with low-wage expectation (by the workers) offers the minimum wage every period in equilibrium. Third, a large firm with high wage expectation offers a high wage every period (and prevents search) in equlibrium. Therefore, in subgame perfect equilibria, a

large firm pays higher wages than a small firm, although we did not impose any heterogeneity in work conditions, worker productivities, or outside opportunities for workers.

In the rest of this section, we assume that the search cost for workers is not too large.

\section{Assumption 1:}

$$
s<\int_{\underline{w}}^{\bar{w}}(x-\underline{w}) f(x) d x .
$$

Proposition 1: Take any subgame where the firm has just paid a wage $u$ and offered a wage $w$ for the next period. Suppose that a worker expects that the firm will continue to offer $w, w, w, \ldots$ in the future. Then, there exists $\underline{\delta} \in(0,1)$ such that for any $\delta \geq \underline{\delta}$, the worker's

\footnotetext{
${ }^{7}$ See for example Fudenberg and Tirole (1996).
} 
optimal strategy is: if $w<\hat{w}_{\delta}$, then always search and accpet any offer not less than $R(w)$, and if $w \geq \hat{w}_{\delta}$, then never search.

The critical level of the firm's future offer $\hat{w}_{\delta}$ is implicitly defined by

$$
\delta \int_{\hat{w}_{\delta}}^{\bar{w}}\left(x-\hat{w}_{\delta}\right) f(x) d x=s .
$$

The reservation level $R(w)$ is implicitly defined by

$$
R[1-\delta F(R)]-\delta \int_{R}^{\bar{w}} x f(x) d x=(1-\delta) w-s .
$$

Proof. See Appendix I.

The critical level $\hat{w}_{\delta}$ is a solution $y$ to

$$
\delta \int_{y}^{\bar{w}} x f(x) d x-\delta[1-F(y)] y=s .
$$

The left hand side of this equation is strictly decreasing in $y$, and Assumption 1 implies that for large enough $\delta$ 's, $\hat{w}_{\delta}$ exists uniquely and satisfies $\hat{w}_{\delta}>\underline{w}$. The positive search cost $s>0$ implies that $\hat{w}_{\delta}<\bar{w}$. Given the workers' optimal strategy by Proposition 1, we show that the minimum wage is a stationary equilibrium wage regardless of the firm size.

Proposition 2: There exists $\underline{\delta} \in(0,1)$ such that for any $\delta \geq \underline{\delta}$, the following strategy combination is a subgame perfect equilibrium:

Firm: Regardless of its size and the past wage offers, offer $\underline{w}$.

Workers: Regardless of the firm's size, if the current offer from the firm is $w$, then search with reservation level $R(\underline{w})+(1-\delta)(w-\underline{w})$.

Proof. See Appendix I.

The idea of the proof is as follows. When the workers become patient (as $\delta$ becomes large), the reservation level $R(\underline{w})+(1-\delta)(w-\underline{w})$ is close to $R(\underline{w})$. Then even if the firm offers a high wage for one period, it cannot reduce the quit rate significantly. Therefore the firm does not have an incentive to deviate. Workers are playing a best response against the firm's stationary offer by a similar logic to Proposition 1. 
Moreover, Fujiwara-Greve (1999a) shows that under $\hat{w}_{\delta}$, the minimum wage is the unique stationary wage. By contrast, any wage level above $\hat{w}_{\delta}$ can be an equilibrium wage if the firm is large. Note that a firm has no incentive to offer more than $\operatorname{Min}\{v, \bar{w}\}$.

Proposition 3: There exists $\underline{\delta} \in(0,1)$ such that for any $\delta \geq \underline{\delta}$ and any $w^{*} \in\left[\hat{w}_{\delta}, \operatorname{Min}\{v, \bar{w}\}\right]$ and any $c \geq\left(w^{*}-\underline{w}\right) /[1-F(R(\underline{w}))]$, the following strategy combination is a subgame perfect equilibrium.

Firm: If the firm is large, start the game by offering $w^{*}$ and continue to offer $w^{*}$ if it has never offered less than $w^{*}$ in the past. If the history includes an offer less than $w^{*}$, offer $\underline{w}$. If the firm is small, offer $\underline{w}$ always.

Workers: If the firm is large and its offer has never been less than $w^{*}$, then do not search. Otherwise search with reservation level $R(\underline{w})+(1-\delta)(w-\underline{w})$ where $w$ is the current offer.

Proof. See Appendix I.

Thus we have derived the firm size-wage effect as subgame perfect equilibria with minimal assumptions on the model. There is no heterogeneity in work conditions or worker productivities (i.e., the same value $v$ is generated at any firm by any worker).

The size-wage differential equilibrium has two parts; a trigger strategy combination for a large firm, and the myopic equilibrium (using Proposition 2) for a small firm or for a large firm after a deviation. The trigger strategy combination part becomes an equilibrium as follows. Thanks to the observability of a large firm's past offers, the current and future workers can punish a large firm if it lowers the wage by starting to search and quitting often. If the players are patient (the discount factor $\delta$ is large) and the turnover cost $c$ is not so small, a large firm finds it more profitable to maintain a high wage and to prevent search than going to the myopic equilibrium.

It is also shown that the level of "high wage" can be any level above which the workers optimally refrain from searching. In the ordinary repeated games, trigger strategy combinations support all the feasible and individually rational payoffs (a folk theorem, see Fudenberg and Tirole, 1996). Our proof is essentially an extension of this result, but in a new framework of endogenous turnover in a game. 


\subsection{Implications}

The fact that large firms are concerned with their "image" or "reputation" is well-known. The reputation is not only what the current workers perceive but also what the potential future workers will know. For a small firm, it is plausible that the future workers do not know its past behavior so well. In a traditional competitive market model or in a one-shot game model, however, the effect of future workers' expectations cannot be incorporated. Our theoretical contribution is that we are able to make a dynamic game model which explicitly includes the current and future worker expectations and relates the observability of firm's actions to the turnover rate.

The equilibria in Proposition 3 show not only the firm size-wage effect, but also that multiple "high wages" are sustained. This is consistent with the ordinary folk theorem of repeated games with no exit. Moreover, Bayard and Troske (1999) gave evidence that the size-wage premium can vary across industries just like the multiple equilibria of Proposition 3. Our conclusion that workers' expectations constitute the unobserved differences causing the firm size-wage effect is new, hence we derive new testable hypotheses and provide empirical evidence to support them.

The firm size effect on wage levels has been tested extensively (e.g., Lester, 1967, Brown and Medoff, 1989, and Bayard and Troske, 1999). To give additional evidence, we focus on the firm size effect on the wage gains after job changes, i.e., the difference between the first wage at the new employer and the last wage at the previous employer. The wage gain is a variable that is strongly affected by how a worker chose the next employer and shows whether the job changes are strategic or not.

Since we only observe the accepted offers, we want to derive effects on the average wage gain given that the offer exceeded the reservation level,

$$
E[x \mid x \geq R(w)]-w=\int_{R(w)}^{\bar{w}} x f(x) d x /[1-F(R(w))]-w,
$$

where $w$ is the previous employer's wage and $R(w)$ is the optimal reservation level from (2).

The average conditional wage gain is dependent on the distribution of the outside offers, but it is unrealistic to assume that the worker knows the exact offer distribution $F$. Instead we assume that the worker uses the observable firm-size distribution as an approximation of the offer distribution. The firm-size wage effect implies that there is a relationship that connects 
firm sizes to the future (stationary) wages. Define a firm-size wage function $w:[\underline{z}, \bar{z}] \rightarrow[\underline{w}, \bar{w}]$ where $\underline{z}$ is the smallest size of a firm and $\bar{z}$ is the largest size, and assume that $w$ is increasing. Let $G:[\underline{z}, \bar{z}] \rightarrow[0,1]$ be the cumulative distribution function of the firms of sizes $z \in[\underline{z}, \bar{z}]$, and let the density function be $g$. Then the expected wage gain conditional on the offer exceeding a reservation level $R^{\prime}$ is

$$
W:=E\left[w(z) \mid z \geq R^{\prime}\right]-w\left(z^{*}\right)=\int_{R^{\prime}}^{\bar{z}} w(z) g(z) d z /\left[1-G\left(R^{\prime}\right)\right]-w\left(z^{*}\right)
$$

where $z^{*}$ is the previous firm's size and $R^{\prime}$ satsifies the modified optimal reservation equation

$$
w\left(R^{\prime}\right)\left[1-\delta G\left(R^{\prime}\right)\right]-\delta \int_{R^{\prime}}^{\bar{z}} w(z) g(z) d z=(1-\delta) w\left(z^{*}\right)-s
$$

Thus, the average wage gain $W$ is influenced by the firm size distribution $G$ and the previous employer's size $z^{*}$, both of which are observable. Notice that the functional form of the average wage gain $W$ and (3) show that only the high-end of the firm size distribution $G$ is important. Hence we look at the effect of the proportion of firms that are larger than the previous employer

$$
m:=\int_{z^{*}}^{\bar{z}} g(z) d z
$$

We divide the effect of changes in $m$ on the wage gain $W$ as follows.

$$
\frac{\Delta W}{\Delta m}=\left.\frac{\Delta W}{\Delta m}\right|_{R^{\prime}}+\left.\frac{\Delta W}{\Delta R^{\prime}}\right|_{m} \cdot \frac{\Delta R^{\prime}}{\Delta m}
$$

where $\left.\frac{\Delta W}{\Delta m}\right|_{R^{\prime}}$ is the effect of $m$ when the reservation level $R^{\prime}$ is fixed and $\left.\frac{\Delta W}{\Delta R^{\prime}}\right|_{m}$ is the effect of the change of the reservation level when the measure $m$ is fixed.

These three effects are analyzed one by one below. Note that the optimal reservation level $R^{\prime}$ is not less than the previous employer size $z^{*}$ due to the increasing wage offer function $w$. [Distribution Effect]: Given the reservation level, the expected conditional offer is higher in industry with a high proportion of firms larger than the previous employer. To see this, consider an increase in $m$ such that $\int_{R^{\prime}}^{\bar{z}} g(z) d z$ increases by a small unit $\Delta$. The numerator of the expected wage $\int_{R^{\prime}}^{\bar{z}} w(z) g(z) d z$ is increased by at least $\Delta w\left(R^{\prime}\right)$, while the denominator is increased by $\Delta$. Therefore $\left.\frac{\Delta W}{\Delta m}\right|_{R^{\prime}}>0$, for not too small $w\left(R^{\prime}\right)$. 
[Reservation Level Effect]: By differentiation, the reservation level increases the average wage gain given $m$ fixed;

$$
\left.\frac{\partial W}{\partial R^{\prime}}\right|_{m}=\frac{g\left(R^{\prime}\right)}{\left[1-G\left(R^{\prime}\right)\right]^{2}} \int_{R^{\prime}}^{\bar{z}}\left[w(z)-w\left(R^{\prime}\right)\right] g(z) d z>0 .
$$

[Effect on the Reservation Level]: As $m$ increases, there are more larger firms in one's opportunity set, and thus the reservation level should be at least weakly increasing. To see this, consider the changes in the left hand side of (3) when $m$ increases $\Delta$ units of $\int_{R^{\prime}}^{\bar{z}} g(z) d z$. The first term $w\left(R^{\prime}\right)\left[1-\delta G\left(R^{\prime}\right)\right]$ increases by $\delta w\left(R^{\prime}\right) \Delta$, while the second term $-\delta \int_{R^{\prime}}^{\bar{z}} w(z) g(z) d z$ decreases at least $\delta \Delta w\left(R^{\prime}\right)$. Thus the left hand side of (3) overall is weakly decreasing. Since the left hand side of (3) is strictly increasing in $R^{\prime}$, the reservation level $R^{\prime}$ that equates the both sides must be weakly increasing in $m$. That is, $\frac{\Delta R^{\prime}}{\Delta m} \geq 0$.

Therefore the total effect (4) of $m$ on the wage gain is positive, and our first hypothesis is;

[H1]: As the proportion of firms that are larger than the previous employer increases, the wage gain after job changes increases.

Second, we show that the average wage gain is negatively correlated with the previous employer's wage, and therefore with its size. To determine the sign of $\frac{\partial W}{\partial z^{*}}$, recall that $w$ is increasing in $z$. The total differentiation of (3) yields

$$
w^{\prime}\left(R^{\prime}\right)\left[1-\delta G\left(R^{\prime}\right)\right] d R^{\prime}=(1-\delta) w^{\prime}\left(z^{*}\right) d z^{*}
$$

hence $\frac{\partial R^{\prime}}{\partial z^{*}}=(1-\delta) w^{\prime}\left(z^{*}\right) /\left[\left(1-\delta G\left(R^{\prime}\right)\right) w^{\prime}\left(R^{\prime}\right)\right]>0$ and when the workers are patient ( $\delta$ large), then this effect is positive but quite small. Therefore

$$
\frac{\partial W}{\partial z^{*}}=\frac{\partial W}{\partial R^{\prime}} \frac{\partial R^{\prime}}{\partial z^{*}}-w^{\prime}\left(z^{*}\right)<0
$$

for large $\delta$ 's. Hence, as the previous employer's size increases, the average wage gain decreases. An intuitive explanation of this effect is that when the previous employer is large, the next employer cannot be so much larger that a worker obtains a large wage gain by moving. Thus our second hypothesis is;

[H2]: Given the outside opportunity distribution, a worker moving from a large firm gets a lower wage increase. 
Finally, the desination firm size increases the wage gain by ordinary firm size-wage effect.

[H3]: Given the outside opportunity distribution and the previous employer size, a worker moving to a bigger firm gets a larger wage increase.

\section{Test}

\subsection{Method and Data}

The above predictions concern the wage gain from changing jobs, and can be tested directly with data with multiple jobs per respondents and the starting and ending wages of each job. Unfortunately, such data are rare since surveys tend to ask for the wages at a given date or when the job is entered (but not left). The best data with such a structure that we are aware of are the German and Norwegian Life History Studies, which are retrospective interview studies of random samples of workers. Of these, the data of Norwegian study are publicly available and are used here.

The data are a probability sample of over 1000 men in each of the 1921, 1931, and 1941 birth cohorts in Norway. Their work histories were coded from entry into the labor force until exit or the survey year 1971, giving multiple jobs per worker. Face-to-face interviews were used to collect work histories along with other important life events (education, marriage, children, sickness). Although based on recall, this method of data collection has been shown to yield high-quality data (Featherman, 1979; Carroll and Mayer, 1986). Each observation has firm size and industry of the job and its starting and ending wages. The direct data on the wage increase reduce the need for controlling for worker characteristics, although we still control for education, experience, and the number of jobs held in the past. Appendix II shows the definitions of the variables used in the analysis. Real (deflated) wages are used.

The data on size distributions are taken from the 1953 and 1963 census of establishments in Norway (Statistisk Sentralbyrå, 1953, 1963). These data display the distributions of estab-

lishment sizes (number of employees) in 9 categories. The measure of the proportion of firms larger than the origin firm is defined by

$$
L=\sum_{i=j+1}^{k} p_{i}
$$


where $p_{i}$ is the proportion of firms in $i$-th size category and $j$ is the worker's current firm-size category (for $j<k$ ). For firms in the largest (50 and over) category, it is set to the proportion of firms of size 200 and over.

We selected labor activity spells that were started after 1950 to avoid the instability of the labor market caused by the war and its aftermath. We omitted jobs entered when the worker was under 18 years old, as many of those were temporary. We omitted farm work, military, unemployment, and partial employment and self-employment, as well as jobs entered with an intervening period of unemployment, partial employment, or self-employment. We did this because even short spells of non-regular employment (especially unemployment) affect the wages in the destination job (Mincer, 1986). Since the census did not report size distributions for public administration, postal service, education and health services, jobs in those industries are omitted. Though the data also show job changes within the firm, we only include job changes across firm. This leaves 7,010 jobs fulfilling our criteria. Of those, jobs entered from origin jobs in government or firms of unspecified size were excluded, leaving 5,087 jobs.

Of the jobs left, 2,916 had data on both origin and destination wages. Missing data on starting or ending wages may cause sample-selection bias because the probability that a wage is reported may depend on covariates of interest to us. This is controlled for by a Tobit type II model (Amemiya, 1985) where the selection equation and the regression equation have joint normal disturbances that may be correlated. That is, we jointly estimate a selection equation of binary outcome $y_{i}$ (observation in sample) and a wage gain equation of $\Delta w_{i}=\log \frac{w_{i, d}}{w_{i, o}}$. The subscripts $\mathrm{d}$ and $\mathrm{o}$ are for the starting wage of the destination job and the ending wage of the origin job, respectively. The estimation model is:

$$
\begin{aligned}
& y_{i}^{*}=\beta^{\prime} \mathbf{x}+\epsilon_{i}, \\
& \Delta w_{i}=\gamma^{\prime} \mathbf{z}+u_{i}, \quad \text { observed if } y_{i}=1 \\
& \text { where } \begin{cases}y_{i}=1 & \text { if } y_{i}^{*}>0 \\
y_{i}=0 & \text { otherwise. }\end{cases}
\end{aligned}
$$

The selection equation uses the worker and firm covariates of the regression equation and variables affecting the recall of wages (the duration and recency of the job). The tables show robust (Eicker-White) standard errors. The Sampsel procedure of Tsp is used for the estimation.

Table 2 contains analysis of subsets of the data defined by occupation or education level. Because estimates of the selection equation are inefficient in such subsets, the models in this 
table instead uses the Heckman (1976) two-step estimation procedure. In this procedure, the inverse Mills ratio $\phi\left(\hat{\beta}^{\prime} \mathbf{x}\right) / \Phi\left(\hat{\beta}^{\prime} \mathbf{x}\right)$ is computed from the selection equation on the full data and added to the wage equation.

\subsection{Results}

Table 1 shows the results of analyses of wage increases due to change in jobs across firms. Moves across and within industries are pooled (but are separated later), and an indicator for across-industry moves is added. The three worker cohorts are analysed together, as analysis of each cohort separately indicated that they did not have different labor market outcomes. Since the measure of the proportion of larger firms in the industry affects both the reservation wage and the probability that a large firm will be entered, this measure and the destination firm sizes are entered both singly and together. In model 3 where all are entered, the coefficient estimate of the proportion of larger firms shows its effect on the wage gain, net of the gain by moving into a large firm. In model 1 where destination firm sizes are omitted, it shows the gross effect of searching for jobs in a labor market with many large firms (the sum of the distribution effect and the expected benefit of entering a large firm).

\section{$=====$ Insert Table 1 about here. $=====$}

Consistent with hypothesis (H1), the proportion of firms larger than the origin firm shows a positive and significant estimate in the models 1 and 3. As one would expect, its magnitude is smaller when the destination firm size is controlled for. Consistent with hypothesis (H2), the origin firm size indicators have negative and significant coefficient estimates in all models, showing that the benefit of changing firms is greater when the origin firm is small. Note that the positive intercepts shows an expected gain from job changes regardless of firm sizes. In our data, $72.7 \%$ of the moves have positive wage gains and $53.0 \%$ have a wage gain of $5 \%$ or higher, suggesting rational search behavior and a high proportion of voluntary job changes. The estimates for destination firm size do not support hypothesis (H3) except when the proportion of larger firms is omitted from the equation. Thus, in the model entering covariates for the proportion of larger firms and the origin firm size, which were derived from our model, there is no remaining destination ffrm size effect on wage increases. The firm-size distribution effect can thus fully account for the observed wage increase when changing firms. 
Estimates of the effect of origin and destination firm size on wage gains from mobility are rarely done, but the negative coefficients of origin firm size and positive coefficients of destination firm size parallell findings by Hannan, Schömann, and Blossfeld (1990), who used the German life-history data. In sum, the findings support our theoretical predictions that wage gains are greater when the worker is (H1) entering an industry with many firms larger than the origin firm and (H2) leaving a small firm.

Apart from these main findings, we also see from Table 1 that the number of previous jobs negatively affects the wage gain. This may be due to personal reputations. Since workers who have moved frequently in the past will be suspected of leaving soon, their wage gains are smaller. An alternative interpretation from human capital theory is that frequent movers neglect to build up their human capital (Mincer and Jovanovic, 1981).

The above analysis pooled data on workers in different jobs and with different educational backgrounds. It is of some interest to investigate whether the findings on industry distribution and firm size effects are similar across subsets of workers, as some argue that worker opportunities vary substantially by worker characteristics and industrial sector. To this end, we conducted analysis of wage gains with more homogeneous subsets of the data. Table 2 contains analyses of the wage gains from job moves on subsets defined by whether the worker changed industry, had a blue or white collar job, and by educational level. The control variables of these analyses are the same as in Model 1, but their coefficient estimates are omitted to conserve space. The number of observations differ substantially among these data sets, and are given next to the coefficient estimates. Because these subsets of data are smaller than the full set, estimates of the selection equation from each dataset would be inefficient. Instead we use the Heckman (1976) two-step procedure by inserting the inverse Mills ratio obtained from the selection equation of the full dataset as a covariate in each model.

\section{$=====$ Insert Table 2 about here. $=====$}

The variables describing the size of the origin firm have rather similar estimates across these data sets. The general conclusion is that leaving medium-size firms gives higher wage gains than leaving large firms, and leaving small firms gives the greatest wage gains. In the two smallest datasets these coefficients are not significant, which could be due to the low number of observations. In the analysis of within-industry mobility, however, the number of observations 
is significantly high that we take the results as suggesting that origin firm size has lower (and perhaps no) effect on wage changes for workers who move within the industry. The proportion of firms larger than the origin firm always has the predicted sign, but is not always significant. It is difficult to interpret this in the small dataset of university-educated persons, but for withinindustry moves it is possible that the industry size distribution has less effect when workers are sufficiently knowledgeable about firms in their industry that they do not need to form expectations by simple rules such as firm size, unlike workers who enter the industry from the outside. Overall the findings are clearly supportive of our theoretical predictions also in these more homogenous subsets of the data.

\section{Conclusion and Discussion}

We have shown that the firm size-wage effect can occur in a single equilibrium with homogeneous workers. A large firm is better off by paying a high wage thanks to the reduced turnover cost, and a small firm cannot imiate a large firm because it cannot establish a good expectation among workers. We also provided a new firm size-wage effect by showing that the firm size distribution affects wage changes after job moves. Both our theoretical result and the evidence are quite new, so we relate our work to the literature.

First we discuss related ideas to our theoretical result. Coles (1998) shows another "firm reputation" model of wage differences. In his model a firm size-wage function is given and then deviations from it is punished by workers' intense search. As we argued in the introduction, the multiple wage equilibrium is obtained due to the equal profit assumption. Since high wage firms have less turnover, they grow to become large firms. We think that the size is not a consequence of high wage, but the high wage is chosen by large firms voluntarily. His "reputation mechanism" is another trigger strategy, but the reputation is only dependent on the firm size-wage function and not on the history of wages. We think that the historical firm behavior affects worker reactions, especially for large firms. Thus we modelled that only large firms are susceptible to the reputation mechanism and that is the unobserved difference generating the equilibrium wage difference. In addition, we show that the large firms earn more total profit than small firms since they can imitate small firms but not the other way around.

In a land market model, Nishimura (1999) gives a related idea of prices serving as a signal 
for future utility. Although his model is one-shot and the equilibrium concept is different, the essense that the prices are strategically set taking the signalling effect into account is close to ours. Spence's famous signalling model (1974) also shows that players choose actions not only for the current benefit but for a long-term considerations. We think that the wages are also a long-term strategy.

As we emphasized, we do not need any physical asymmetry (work conditions, productivities etc.) among the firms of different size or among the workers at different size firms. This is theoretically a stronger result than other models generating the firm size-wage effect under asymmetry such as Weiss and Landau (1984). It is easy, though, to extend our model to allow asymmetries such as worker skills and effort. A large firm has an additional benefit of paying a high wage when its workers can increase productivity knowing that they will not quit so often. Thus the firm size-wage effect will be strengthened. It is also possible to extend the model to include multiple firms. Fujiwara-Greve (1999a) shows that the trigger stratgy used in Proposition 3 can constitute a Nash equilibrium of a market game where many firms and workers search each other simultaneously.

Finally we emphasize that our empirical analysis of firm size distribution is unprecedented. The measure of the proportion of larger firms than the previous employer captured the effect of firm size distribution in wage changes completely, because entering the destination firm size did not give any additional effect. As an empirical analysis, accounting fully of an effect is rare and valued. Thus our approach to look at the wage gains of job changes compensates well the studies of firm size effect on wage levels (e.g., Brown and Medoff, 1989, and Bayard and Troske, 1999). Moreover, the empirical analyses clearly show that the job changes are strategic (by positive wage gain and firm size distribution effect). Thus our result strongly supports the game model of wage determination, with both firms and workers bahaving strategically. 


\section{Appendix I: Proofs of the Propositions}

\section{Proof of Proposition 1.}

Under the stationary expectation, a worker's optimization problem is a stationary discounted dynamic programming problem, which is shown to have a stationary optimal solution (see Blackwell, 1965). We will show (A) the value function of the dynamic programming problem given that a worker searches every period with a reservation level $R$, (B) the optimal reservation level that maximizes the value function, $(\mathrm{C})$ the condition under which not searching in any period is optimal, and (D) the condition under which stationary search is optimal.

(A) Value function under search: Suppose that the firm has paid $u$ and offers $w$ forever after.

The value function (the total expected discounted payoff) when the worker searches every period and accepts any offer not less than $R$ is computed as follows. (Note that the reservation strategy is optimal because of the stationary offers.) In this period, the stage payoff is $u-\frac{s}{1-\delta}$. In the next period, there are two cases. If an offer $x \geq R$ arrives, he/she takes it and start

receiving $x$ from next period on. The total expected payoff of this case is $\int_{R}^{\bar{w}} \frac{x}{1-\delta} f(x) d x$. If the offer was less than $R$ (with probability $F(R)$ ), the situation becomes just like this period but with the initial payment $w$. Let $V_{S}\left(u, w^{\infty}\right)$ be the total expected discounted payoff of this strategy given this period payment $u$ and the future offers $w, w, \ldots$. The second case gives $V_{S}\left(w, w^{\infty}\right)$. Thus,

$$
V_{S}\left(u, w^{\infty}\right)=u-\frac{s}{1-\delta}+\delta \int_{R}^{\bar{w}} \frac{x}{1-\delta} f(x) d x+\delta F(R) V_{S}\left(w, w^{\infty}\right),
$$

and analogously

$$
V_{S}\left(w, w^{\infty}\right)=w-\frac{s}{1-\delta}+\delta \int_{R}^{\bar{w}} \frac{x}{1-\delta} f(x) d x+\delta F(R) V_{S}\left(w, w^{\infty}\right)
$$

One can solve (6) and plug in (5) to obtain the explicit form of $V_{S}\left(u, w^{\infty}\right)$.

(B) An optimal reservation level is $R$ that maximizes $V_{S}(u, w)$. Since $V_{S}(u, w)$ and $V_{S}(w, w)$ differ only in the first constant term, we differentiate $V_{S}(w, w)$ to find the optimal $R$. It is easy to show that the first order condition $\frac{\partial V_{S}}{\partial R}=0$ is necessary and sufficient to determine the optimal reservation level, and the first order condition is equivalent to (2).

We show that the solution $R(w)$ to $(2)$ exists and is unique under Assumption 1. Define 
the left hand side of (2) as

$$
\ell(R):=R(1-\delta F(R))-\delta \int_{R}^{\bar{w}} x f(x) d x .
$$

By differentiation, $\ell$ is strictly increasing in $R$. Thus it suffices to show that $\ell(\underline{w})<(1-\delta) w-s<$ $\ell(\bar{w})$. Plugging in $R=\underline{w}$ we obtain

$$
\ell(\underline{w})=\underline{w}-\delta \int_{\underline{w}}^{\bar{w}} x f(x) d x<-s
$$

by Assumption 1. Moreover,

$$
\ell(\bar{w})=(1-\delta) \bar{w}>(1-\delta) w-s
$$

Hence there is a unique optimal reservation level $R(w)$.

(C) We prove that when the firm's stationary offer satsifies $w \geq \hat{w}_{\delta}$, then the opimal strategy is not to search in any period by showing that a one-step deviation does not give a larger total payoff. This is sufficient thanks to the result that in a bounded discounted dynamic programming problem, an unimprovable strategy in single-step is optimal. See for example Kreps (1990), Appendix Two Proposition 4.

Take a subgame where the firm just paid $u$ and offers $w, w, \ldots$ forever after. The total expected discounted payoff of the non-search strategy is $u+\delta \frac{w}{1-\delta}$. If the worker deviates and searches for one period with a reservation level $R^{*}$, the total discounted expected payoff is

$$
D=u-\frac{s}{1-\delta}+\delta \int_{R^{*}}^{\bar{w}} \frac{x}{1-\delta} f(x) d x+\delta F\left(R^{*}\right) \frac{w}{1-\delta}
$$

By differentiation, the optimal reservation level after a deviation is $w$. Substituting this and using (1), we get

$$
u+\delta \frac{w}{1-\delta} \geq D \Longleftrightarrow s \geq \delta \int_{w}^{\bar{w}}(x-w) f(x) d x \Longleftrightarrow w \geq \hat{w}_{\delta} .
$$

Hence as long as $w \geq \hat{w}_{\delta}$, it is optimal not to search.

(D) Suppose that the expected stationary wage is $w<\hat{w}_{\delta}$. Then the constant search strategy with the optimal reservation level $R(w)$ gives the total expected discounted payoff of $V_{S}\left(u, w^{\infty}\right)$ with $R=R(w)$. If a worker deviates and did not search for one period, the total expected discounted payoff is

$$
D^{\prime}=u+\delta V_{S}\left(w, w^{\infty}\right)
$$


with $R=R(w)$. Hence a deviation is not benefitial if

$$
V_{S}\left(u, w^{\infty}\right) \geq D^{\prime} \Longleftrightarrow w[1-\delta F(w)]-\delta \int_{w}^{\bar{w}} x f(x) d x \leq(1-\delta) w-s
$$

which is equivalent to $w \leq \hat{w}_{\delta}$.

Lemma 1: Under Assumption 1, as $\delta$ converges to one, the optimal reservation level $R(\underline{w})$ from (2) converges to the unique $R^{* *}$ which satisfies

$$
R^{* *}\left(1-F\left(R^{* *}\right)\right)-\int_{R^{* *}}^{\bar{w}} x f(x) d x=-s .
$$

Moreover $\underline{w}<R^{* *}<\bar{w}$.

Proof of Lemma 1 . As $\delta \rightarrow 1$, the left hand side of $(2)$ converges to $\ell^{*}(R):=R(1-F(R))-$ $\int_{R}^{\bar{w}} x f(x) d x$ while the right hand side of $(2)$ converges to $-s$. By differentiation, $\ell^{*}$ is strictly increasing in $R$. By Assumption 1,

$$
\ell^{*}(\underline{w})=\underline{w}-\int_{\underline{w}}^{\bar{w}} x f(x) d x<-s
$$

which implies that the solution $R^{* *}$ to $\ell^{*}(R)=-s$ strictly exceeds $\underline{w}$. Since $\ell^{*}(\bar{w})=0$, the solution to $\ell^{*}(R)=-s$ is strictly smaller than $\bar{w}$.

\section{Proof of Proposition 2.}

We show (A) for lage $\delta$ 's, in any subgame, the suggested strategy for the workers is optimal given that the firm follows its strategy, and (B) for large $\delta$ 's, the firm's strategy is optimal in any subgame given the workers'.

(A) Take any subgame where the firm has just paid $u$ and offered $w$ for the next period. (It is possible that $u=w$, when it is a new employee.) Given the firm's strategy, the future offers are $\underline{w}, \underline{w}, \ldots$ In this generic subgame, we show that the optimal reservation level given search is $R(\underline{w})+(1-\delta)(w-\underline{w})$, and then search is better than deviating to not to search for one period.

First, notice that from next period on, (if this worker did not quit in this period), the worker faces a constant offer $\underline{w}, \underline{w}, \ldots$ In Proposition 1, we have computed the optimal reservation level $R(\underline{w})$ for next period on. Thus, the optimal value of the constant search from next period on is

$$
V_{S}\left(w, \underline{w}^{\infty}\right)=w-\frac{s}{1-\delta}+\delta \int_{R(\underline{w})}^{\bar{w}} \frac{x}{1-\delta} f(x) d x+\delta F(R(\underline{w})) V_{S}\left(\underline{w}, \underline{w}^{\infty}\right)
$$


and hence

$$
V_{S}\left(w, \underline{w}^{\infty}\right)=V_{S}\left(\underline{w}, \underline{w}^{\infty}\right)-(w-\underline{w})=R(\underline{w}) /(1-\delta)-(w-\underline{w}) .
$$

The last equality uses the the first order condition $V_{S}\left(\underline{w}^{\infty}\right)=\frac{R(\underline{w})}{1-\delta}$.

Going back to the current period, the value of constant search with reservation level $y$ is

$$
V_{S}\left(u, w, \underline{w}^{\infty}\right)=u-\frac{s}{1-\delta}+\delta \int_{y}^{\bar{w}} \frac{x}{1-\delta} f(x) d x+\delta F(y) V_{S}\left(w, \underline{w}^{\infty}\right) .
$$

By differentiation, $\frac{\partial V_{S}(u, w, w)}{\partial y}=0$ implies that the optimal reservation level $y$ is

$$
y=R(\underline{w})+(1-\delta)(w-\underline{w}) .
$$

Thus the reservation level in the suggested strategy is optimal.

Now suppose that the worker is at the search decision node. If he/she deviates for one period and does not search but conforms to the constant search strategy from the next period on, the total expected discounted payoff is

$$
D=u+\delta V_{S}\left(w, \underline{w}^{\infty}\right)
$$

Hence $V_{S}\left(u, w, \underline{w}^{\infty}\right) \geq D$ if and only if

$$
s \leq \delta \int_{R(\underline{w})+(1-\delta)(w-\underline{w})}^{\bar{w}}(x-R(\underline{w})+(1-\delta)(w-\underline{w})) f(x) d x .
$$

Assumption 1 is equivalent to

$$
s<\lim _{\delta \rightarrow 1} \delta \int_{R(\underline{w})+(1-\delta)(w-\underline{w})}^{\bar{w}}(x-R(\underline{w})+(1-\delta)(w-\underline{w})) f(x) d x .
$$

Therefore there exists $\delta^{*} \in(0,1)$ such that for any $\delta \geq \delta^{*}, V_{S}\left(u, w, \underline{w}^{\infty}\right) \geq D$, i.e., the worker does not devieate to no-search.

(B) We show that the firm does not deviate from constant $\underline{w}, \underline{w}, \ldots$ for one period. In the subgames where the firm has a new employee, if the firm follows the the constant offer strategy $\underline{w}, \underline{w}, \ldots$, the total expected discounted payoff $\Pi\left(\underline{w}^{\infty}\right)$ satisfies

$$
\Pi\left(\underline{w}^{\infty}\right)=v-\underline{w}+\delta\{1-F(R(\underline{w}))\}\left[\Pi\left(\underline{w}^{\infty}\right)-c\right]+\delta F(R(\underline{w})) \Pi\left(\underline{w}^{\infty}\right)
$$

On the other hand, if the firm offers $w>\underline{w}$ for this period, it can reduce the quit rate by pushing up the worker's reservation level to $R(\underline{w})+(1-\delta)(w-\underline{w})$. However, if the worker 
quits nevertheless (with probability $1-F(R(\underline{w}))+(1-\delta)(w-\underline{w}))$ ), it will start offering $\underline{w}$ from next period and the continuation value is $\Pi\left(\underline{w}^{\infty}\right)-c$. If the worker stayed this period, the firm pays $w$ next period instead of $\underline{w}$, and then conforms to offering $\underline{w}, \underline{w}, \ldots$ Thus the total expected discounted payoff becomes

$$
\begin{aligned}
D\left(w, \underline{w}^{\infty}\right)= & v-w+\delta\{1-F(R(\underline{w}))+(1-\delta)(w-\underline{w})\}\left[\Pi\left(\underline{w}^{\infty}\right)-c\right] \\
& +\delta F(R(\underline{w})+(1-\delta)(w-\underline{w}))\left[\Pi\left(\underline{w}^{\infty}\right)-w+\underline{w}\right] .
\end{aligned}
$$

Therefore $\Pi\left(\underline{w}^{\infty}\right) \geq D\left(w, \underline{w}^{\infty}\right)$ if and only if

$$
w-\underline{w} \geq \delta\{F(R(\underline{w})+(1-\delta)(w-\underline{w}))-F(R(\underline{w}))\}[c-(w-\underline{w})] .
$$

Since $\lim _{\delta \rightarrow 1} R(\underline{w})+(1-\delta)(w-\underline{w})=\lim _{\delta \rightarrow 1} R(\underline{w})=R^{* *}$ (see Lemma 1 ), the right hand side of the above inequality goes to zero as $\delta$ approaches to one. Hence there exists $\delta^{* *} \in(0,1)$ such that for any $\delta \geq \delta^{* *}, \Pi\left(\underline{w}^{\infty}\right) \geq D\left(w, \underline{w}^{\infty}\right)$. Thus, the firm does not deviate in any subgame where it has a new employee.

Take any subgame where the firm offered $u$ in the previous period and the worker did not quit. Then this period payment is $u$. If the firm offers $w$ for one period, and then conforms to $\underline{w}, \underline{w}, \ldots$, the total expected discounted payoff is

$$
\begin{aligned}
\Pi^{\prime}\left(u, w, \underline{w}^{\infty}\right)= & v-u+\delta\{1-F(R(\underline{w}))+(1-\delta)(w-\underline{w})\}\left[\Pi\left(\underline{w}^{\infty}\right)-c\right] \\
& +\delta F(R(\underline{w})+(1-\delta)(w-\underline{w}))\left[\Pi\left(\underline{w}^{\infty}\right)-w+\underline{w} .\right.
\end{aligned}
$$

By differentiation,

$$
\left.\left.\frac{\partial \Pi^{\prime}}{\partial w}=\delta(1-\delta) f(R(\underline{w}))+(1-\delta)(w-\underline{w})\right)[c-(w-\underline{w})]-\delta F(R(\underline{w}))+(1-\delta)(w-\underline{w})\right) .
$$

When $\delta$ approaches to one, the derivative becomes $-F\left(R^{* *}\right)<0$. Hence the optimal deviation for large $\delta$ is $\underline{w}$. Therefore there exists $\delta^{* * *} \in(0,1)$ such that for any $\delta \geq \delta^{* * *}$, the firm does not deviate. Lastly let $\underline{\delta}=\operatorname{Max}\left\{\delta^{*}, \delta^{* *}, \delta^{* * *}\right\}$.

\section{Proof of Proposition 3.}

By Proposition 2, the suggested strategy combination is a subgame perfect equilibrium if the firm is small or if they are in a subgame where the firm has offered a wage less than $w^{*}$. We show that the strategy combination is a subagme perfect equilibrium if the firm is large and it has never offered less than $w^{*} \in\left[\hat{w}_{\delta}, \operatorname{Min}\{v, \bar{w}\}\right]$. 
(A) Workers: Suppose that the firm has maintained wages not less than $w^{*}$ in the past, paid $u \geq w^{*}$, and offered $w \geq w^{*}$ for the next period. If the current worker follows the suggested strategy, he/she does not search and the total expected discounted payoff is $u+\delta w+\delta^{2} w^{*} /(1-\delta)$ since the firm will offer $w^{*}$ from the next period on. If the worker deviates one period and searches with reservation level $r$, he/she receives

$$
D=u-\frac{s}{1-\delta}+\delta \int_{r}^{\bar{w}} \frac{x}{1-\delta} f(x) d x+\delta F(r)\left[w+\delta \frac{w^{*}}{1-\delta}\right] .
$$

By differentiation, the optimal reservation level is $r=(1-\delta) w+\delta w^{*}$ and note that this is not less than $\hat{w}_{\delta}$. The deviation value $D$ is not more than $u+\delta w+\delta^{2} w^{*} /(1-\delta)$ if and only if

$$
s+\delta \int_{z}^{\bar{w}}(z-x) f(x) d x \geq 0 .
$$

Since $r \geq \hat{w}_{\delta}$ and $\int_{y}^{\bar{w}}(y-x) f(x) d x$ is increasing in $y$, Assumption 1 implies that

$$
s+\delta \int_{r}^{\bar{w}}(r-x) f(x) d x \geq s+\delta \int_{\hat{w}_{\delta}}^{\bar{w}}\left(\hat{w}_{\delta}-x\right) f(x) d x>0 .
$$

Therefore the worker does not deviate.

(B) Firm: Take a subgame where it has paid $u$. Note that offering $w^{*}$ is enough to prevent search, the firm has no incentive to offer more than $w^{*}$. If it offers less than $w^{*}$, the optimal offer is the minimum wage $\underline{w}$ thanks to Proposition 2, for sufficiently large $\delta$. Then its total expected discounted payoff is

$$
\Pi\left(u, \underline{w}^{\infty}\right)=v-u+\delta\{1-F(R(\underline{w}))\}\left[\Pi\left(\underline{w}^{\infty}\right)-c\right]+\delta F(R(\underline{w})) \Pi\left(\underline{w}^{\infty}\right)
$$

where $\Pi\left(\underline{w}^{\infty}\right)$ is determined by (7) in the proof of Proposition 2 so that

$$
\Pi\left(\underline{w}^{\infty}\right)=[v-\underline{w}-\delta\{1-F(R(\underline{w}))\} c] /(1-\delta) .
$$

If the firm follows the suggested strategy $w^{*}, w^{*}, \ldots$, the total payoff is $v-u+\delta \frac{v-w^{*}}{1-\delta}$. Thus, the suggested strategy is unimprovable if and only if

$$
v-u+\delta \frac{v-w^{*}}{1-\delta} \geq \Pi\left(u, \underline{w}^{\infty}\right)=\Pi\left(\underline{w}^{\infty}\right)-u+\underline{w} \Longleftrightarrow c \geq \frac{w^{*}-\underline{w}}{1-F(R(\underline{w}))} .
$$

Therefore for sufficiently large $\delta$, no player deviates for one period in any subgame, thus the suggested strategy combination is a subgame perfect equilibrium. 
APPENDIX II

VARIABLE DEFINITIONS

\begin{tabular}{|c|c|c|}
\hline Variable & Definition & Source \\
\hline Starting wages & $\begin{array}{l}\text { Monthly income from employer at start of job spell, } \\
\text { deflated to } 1968 \text { kroner }\end{array}$ & NLHS \\
\hline Ending wages & $\begin{array}{l}\text { Monthly income from employer at end of job spell, } \\
\text { deflated to } 1968 \text { kroner }\end{array}$ & NLHS \\
\hline Junior high school & $\begin{array}{l}1 \text { if completed junior high school, but not senior high } \\
\text { school }\end{array}$ & NLHS \\
\hline Senior high school & $\begin{array}{l}1 \text { if completed senior high school, but not started } \\
\text { university studies }\end{array}$ & NLHS \\
\hline $1+$ years of university & $\begin{array}{l}1 \text { if completed one or more years of college or } \\
\text { university }\end{array}$ & NLHS \\
\hline Labor force experience & Time since entry into labor force in months & NLHS \\
\hline Previous jobs & Logged number of jobs previously held by worker & NLHS \\
\hline $\begin{array}{l}\text { Moved across } \\
\text { industries }\end{array}$ & $\begin{array}{l}1 \text { if origin and destination industry (2-digit code) is } \\
\text { different }\end{array}$ & NLHS \\
\hline Industry size diversity & $\begin{array}{l}\text { One minus Herfindahl concentration index of } \\
\text { establishment size in 2-digit industry }\end{array}$ & Census \\
\hline Industry size & $\begin{array}{l}\text { Number of employees in the industry, measured in } \\
\text { millions. }\end{array}$ & Census \\
\hline Mean wage & $\begin{array}{l}\text { Industry wage payment per worker, deflated to } 1968 \\
\text { kroner }\end{array}$ & Census \\
\hline Government & $\begin{array}{l}1 \text { if the destination employer was a government- } \\
\text { owned organization }\end{array}$ & NLHS \\
\hline Private $5-49$ & $\begin{array}{l}1 \text { if the employer (origin or destination) was a private } \\
\text { firm with 5-49 workers }\end{array}$ & NLHS \\
\hline Private $50+$ & $\begin{array}{l}1 \text { if the employer (origin or destination) was a private } \\
\text { with } 50 \text { or more workers }\end{array}$ & NLHS \\
\hline Proportion larger firms & $\begin{array}{l}\text { Proportion of establishments in destination industry } \\
\text { larger than origin employer }\end{array}$ & $\begin{array}{l}\text { NLHS / } \\
\text { Census }\end{array}$ \\
\hline
\end{tabular}




\section{References}

Abowd J.M., F. Karamarz, and D. N. Margolis. (1999) "High Wage Workers and High Wage Firms", Econometrica, Vol. 67, No. 2, pp. 251-333.

Amemiya T. (1985) Advanced Econometrics, Harvard University Press.

Bayard K. and K. R. Troske (1999) "Examining the Employer-Size Wage Premium in the Manufacturing, Retail Trade, and Service Industries Using Employer-Employee Matching Data", American Economic Review, Vol. 89, No. 2, 99-103.

Blackwell, D. (1965) "Discounted dynamic programming", Annals of Math. Stat. Vol. 36, pp. 226-235.

Brown, C. and J. Medoff (1989) "The Employer Size-Wage Effect", Journal of Political Economy, Vol. 97, No. 5, pp. 1027-1059.

Bulow J. I. and L. H. Summers (1986) "A Theory of Dual Labor Markets with Application to Industrial Policy, Discrimination, and Keynesian Unemployment", Journal of Labor Economics, Vol. 4, No. 2, pp. 376-414.

Burdett K. and D. T. Mortensen (1998) "Wage Differentials, Employer Size, and Unemployment", International Economic Review, Vol. 39, No. 2, 257-273.

Carroll, G. R., and K. U. Mayer (1986) "Job-Shift Patterns in the Federal Republic of Germany: The Effects of Social Class, Industrial Sector, and Organizational Size", American Sociological Review Vol. 51, pp. 323-341.

Coles, M. G. (1998) "Equilibrium Wage Dispersion, Firm Size and Growth", Manuscript, University of Essex.

Featherman, D. (1979) "Retrospective Longitudinal Research: Methodological Considerations", Journal of Economics and Business Vol. 32, pp. 152-169.

Fudenberg, D. and J. Tirole (1996) Game Theory, MIT Press.

Fujiwara-Greve, T. (1999a) "Wage Differentials as Reputation Equilibria", Manuscript, Keio University.

Fujiwara-Greve, T. (1999b) "Repeated Games with Outside Offers", Manuscript, Keio University.

Hannan, M. T., Schömann K. and Blossfeld H. (1990) "Sex and Sector Differences in the Dynamics of Wage Growth in the Federal Republic of Germany", American Sociological 
Review, Vol. 55, pp. 694-713.

Heckman, J. (1976) "The Common Structure of Statistical Models of Truncation, Sample Selection and Limited Dependent Variables and a Simple Estimator for Such Models", Annals for Economic and Social Measurement, Vol. 5, pp. 475-492.

Kalleberg, A. L. and M. E. Van Buren (1996). "Is Bigger Better: Explaining the relationship between organization size and job rewards," American Sociological Review, Vol. 61, No. 2, pp. 47-66.

Kreps, D. (1990) A Course in Microeconomic Theory, Princeton University Press, Princeton, NJ, 1990.

Lester, R. (1967) "Pay Differentials by Size of Establishment", Industrial Relations, Vol. 7, pp. 57-67.

Martinelli, C. (1997) "Small Firms, Borrowing Constraints, and Reputation", Journal of Economic Bahvior \& Organization, Vol. 33, No. 1, pp. 91-105.

McMillan J. and M. Rothschild (1994) "Search", in Handbook of Game Theory (R. Aumann and S. Hart, Eds.) Vol. 2, pp.905-927, North-Holland, New York.

Mincer, J.,(1986) "Wage Changes in Job Changes", Research in Labor Economics, Vol. 8, pp. $171-197$.

Mincer, J. and B. Jovanovic (1981) "Labor Mobility and Wages", in S. Rosen ed., Studies in Labor Markets: Chicago University Press, pp. 21-64.

Nishimura, K. (1999) "Expectations Heterogeneity and Excessive Price Sensitivity in the Land Market", Japanese Economic Review, Vol. 50, No. 1, pp.26-43.

Shapiro, C. and J. E. Stiglitz (1984) "Equilibrium Unemployment as a Worker Discipline Device", American Economic Review, Vol. 74, No. 3, pp. 433-444.

Spence, A. M. (1974) Market Signalling, Harvard University Press.

Statistisk Sentralbyrå(1953) Bedriftstelling i Norge 24. april 1953. [= Census of Establishments April 24, 1953]. (Oslo, Norway: Statistisk Sentralbyrå).

Statistisk Sentralbyrå(1963) Bedriftstelling 1963. [= Census of Establishments 1963]. (Oslo, Norway: Statistisk Sentralbyrå).

Thaler, R.H. (1989) "Anomalies: Interindustry Wage Differentials", Journal of Economic Perspectives, Vol. 3, No. 2, pp. 181-193. 
Troske, K. (1999) "Evidence on the Employer Size-Wage Premium from Worker-Establishment Matched Data", The Review of Economics and Statistics, Vol. 81, No. 1, pp. 15-26.

Weiss, A. and J. Landau (1984) "Wages, Hiring Standards, and Firm Size", Journal of Labor Economics, Vol. 2, No. 4, pp. 477-499.

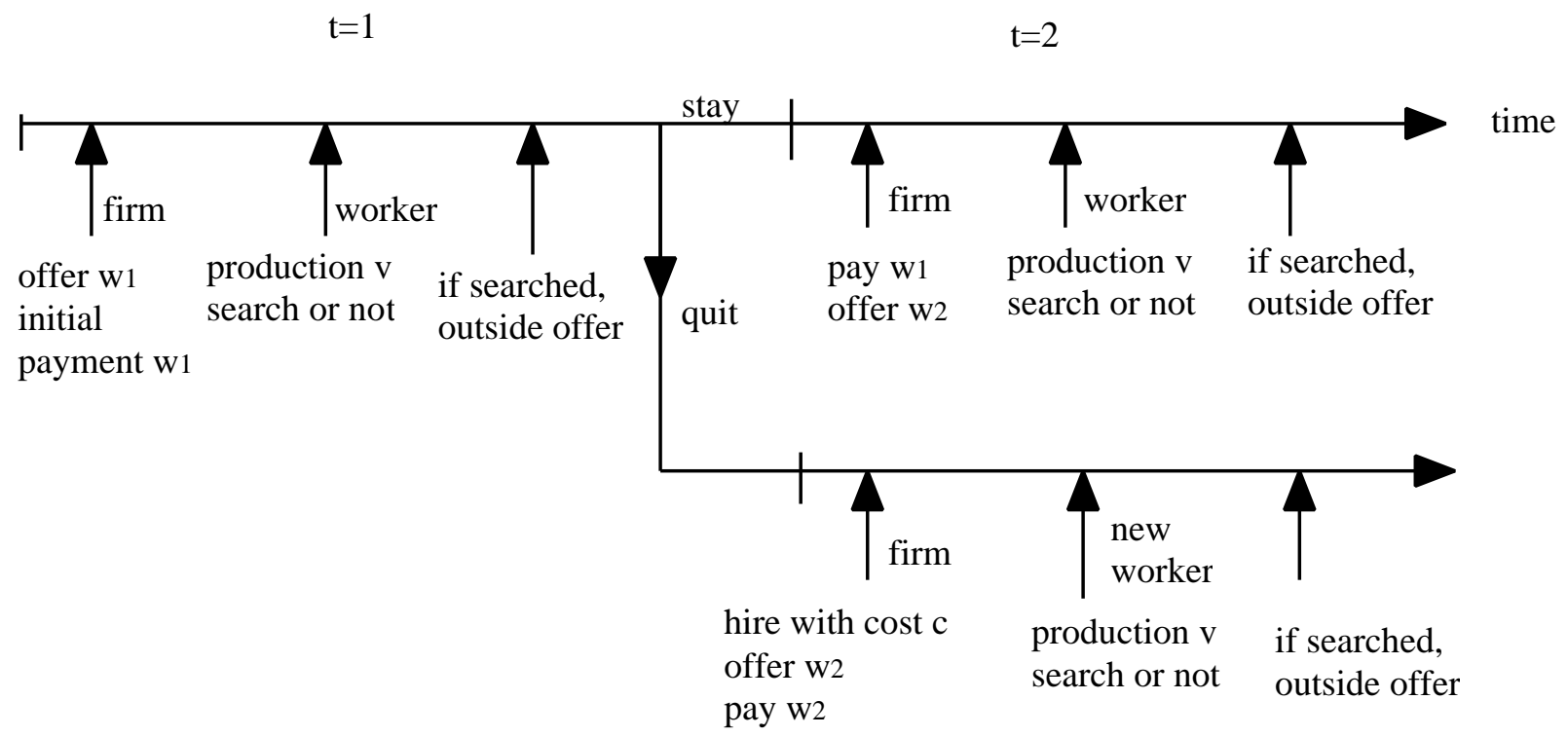

Figure 1: Timing of the game 
TABLE 1

ESTIMATES OF WAGE CHANGE FROM INTERFIRM JOB

CHANGE, MAXIMUM LIKELIHOOD SAMPLE SELECTIVITY

\begin{tabular}{lrrr}
\hline \hline & \multicolumn{3}{c}{ Model } \\
& \multicolumn{1}{c}{$(1)$} & \multicolumn{1}{c}{$(2)$} & \multicolumn{1}{c}{$(3)$} \\
\hline Intercept & 1.004 & 1.065 & 0.987 \\
& $(0.139)$ & $(0.147)$ & $(0.141)$ \\
Worker control variables: & & & \\
Junior high education & -0.031 & -0.016 & -0.018 \\
& $(0.023)$ & $(0.024)$ & $(0.024)$ \\
Senior high eduction & $-0.076^{* *}$ & $-0.096^{* *}$ & $-0.094^{* *}$ \\
& $(0.028)$ & $(0.030)$ & $(0.030)$ \\
1+ years of university & -0.051 & -0.058 & -0.055 \\
& $(0.036)$ & $(0.036)$ & $(0.036)$ \\
Labor force experience & 0.00018 & 0.00017 & 0.00017 \\
& $(0.00012)$ & $(0.00012)$ & $(0.00021)$ \\
Previous jobs & $-0.083^{* *}$ & $-0.089^{* *}$ & $-0.089^{* *}$ \\
& $(0.021)$ & $(0.021)$ & $(0.021)$
\end{tabular}

Industry control variables:

Moved across industry

$\begin{array}{rrr}-0.026 & -0.027 & -0.027 \\ (0.017) & (0.017) & (0.017) \\ -0.678^{* *} & -0.511^{* *} & -0.660^{* *} \\ (0.147) & (0.140) & (0.151) \\ 0.002 & 0.005 & 0.002 \\ (0.010) & (0.011) & (0.011) \\ 0.010 & 0.020 & 0.011 \\ (0.014) & (0.015) & (0.014)\end{array}$

Destination industry $(\mathrm{H} 1)$ :
$0.207^{* *}$
$0.172 *$
$(0.070)$
(0.075)

Origin firm (H2):

Private, 5-49 workers

$$
\begin{array}{rrr}
-0.083^{*} & -0.079^{*} & -0.083^{* *} \\
(0.032) & (0.032) & (0.032) \\
-0.170^{* *} & -0.172^{* *} & -0.175^{* *} \\
(0.032) & (0.033) & (0.033)
\end{array}
$$

Private-sector, 50+ workers

Destination firm (H3):

Government owned

$\begin{array}{rr}0.066 & 0.058 \\ (0.055) & (0.055) \\ 0.041 & 0.032 \\ (0.028) & (0.029) \\ 0.067^{*} & 0.048 \\ (0.029) & (0.031)\end{array}$

Private, 5-49 workers

Private, 50+ workers 
Note: Eicker-White (robust) standard errors are in parantheses.

Significance levels from two-sided tests denoted by symbols $*(p<.05)$ and $* *(\mathrm{p}<.01)$

TABLE 2

ESTIMATES OF WAGE CHANGE FROM INTERFIRM JOB CHANGE, TWO STAGE SAMPLE SELECTIVITY

\begin{tabular}{|c|c|c|c|c|}
\hline \multirow[b]{2}{*}{ Subset } & \multirow[b]{2}{*}{ Observations } & \multicolumn{2}{|c|}{ Origin firm } & \multirow{2}{*}{$\begin{array}{c}\text { Destination } \\
\text { industry } \\
\text { Prop. }> \\
\text { origin }\end{array}$} \\
\hline & & $\begin{array}{l}5-49 \\
\text { workers }\end{array}$ & $\begin{array}{l}\text { Over } 50 \\
\text { workers }\end{array}$ & \\
\hline Across industry & 1981 & $-0.111 * *$ & $-0.224 * *$ & $0.224 *$ \\
\hline Within industry & 935 & -0.033 & -0.074 & 0.023 \\
\hline Until junor high school & 1926 & -0.052 & $-0.166^{* *}$ & $0.184^{*}$ \\
\hline Senior high school & 667 & $-0.190^{* *}$ & $-0.271 * *$ & $0.430 * *$ \\
\hline University & 323 & -0.082 & -0.085 & 0.002 \\
\hline Blue-collar workers & 2427 & $-0.096^{*}$ & $-0.200 * *$ & 0.163 \\
\hline White-collar workers & 489 & -0.077 & $-0.120 \dagger$ & $0.341 *$ \\
\hline
\end{tabular}

Note: Eicker-White (robust) standard errors are used for hypothesis tests. Significance levels from two-sided tests denoted by symbols $\dagger(\mathrm{p}<.10),{ }^{*}(\mathrm{p}<.05)$, and ${ }^{* *}(\mathrm{p}<.01)$. 